\title{
Importância da transfaunação no tratamento da acidose láctica ruminal aguda induzida em cabras e ovelhas ${ }^{1}$
}

\author{
Priscilla F.V. Pereira ${ }^{2}$, Fernanda T.N.A.M. Romão ${ }^{3}$, Eduardo M. Penzeti², \\ João F.Z. Sanches ${ }^{4}$, Juliana M. Curti², Karina K.M.C. Flaiban ${ }^{4}$ e Júlio A.N. Lisbôa ${ }^{2 *}$
}

\begin{abstract}
Pereira P.F.V., Romão F.T.N.A.M., Penzeti E.M., Sanches J.F.Z., Curti J.M., Flaiban K.K.M.C. \& Lisbôa J.A.N. 2018. [Value of transfaunation for the treatment of induced ruminal lactic acidosis in goats and sheep.] Importância da transfaunação no tratamento da acidose láctica ruminal aguda induzida em cabras e ovelhas. Pesquisa Veterinária Brasileira 38(4):670-678. Departamento de Clínicas Veterinárias, Universidade Estadual de Londrina, Rodovia Celso Garcia Cid PR-445 Km 380, Campus Universitário, Londrina, PR 86057-970, Brazil. E-mail: janlisboa@uel.br

The aim of this study was to evaluate the value of transfaunation in the treatment and recovery of goats and sheep with acute rumen lactic acidosis (ARLA) experimentally induced. Six goats $(41.2 \pm 5.6 \mathrm{~kg})$ and six sheep $(46.8 \pm 4.57 \mathrm{~kg})$, non-pregnant and non-lactating, received $15 \mathrm{~g}$ of sucrose per kilogram of body weight for the disease induction. The ARLA was induced in each animal twice with an interval of 30 days after full recovery of the first induction. Therapeutic procedures consisted in removal of the rumen fluid content by washing and siphoning with an esophageal tube and correction of metabolic acidosis with intravenous electrolyte solutions containing sodium lactate or sodium bicarbonate. The transfaunation was part of only one of each animal treatment and consisted in administration of two liters of rumen fluid colleted from a healthy cow. Complete recovery was assessed by physical examinations and rumen fluid examinations up to four days after therapeutic procedures. The efficacy of treatment protocols, with or without transfaunation was compared. The protocol used was effective in induce the disease and goats and sheep showed clinical signs of maximum intensity (apathy, rumen stasis, abdominal distension, diarrhea and moderate dehydration) 16 hours after the intraruminal administration of sucrose. At this moment, the characteristics of ruminal fluid were similar to the typical ARLA. The frequency of ruminal movements became normal on the third day after therapeutic procedures, with no difference between species, and regardless transfaunation. The ruminal fluid transfer did not accelerate the recovery of appetite, considered normal only on the fourth day after treatment in both species. When transfauntation was received, goats and sheep showed recovery of characteristics of color, odor and consistency faster than when they did not receive. The fermentative activity of the rumen microbiota was not impacted by transfaunation and normalized two and three days after therapeutic procedures in sheep and goats, respectively. The transfaunation promoted faster return of the protozoa population, which was observed 24 hours after therapeutic procedures in both species. When the animals did not receive transfaunation, the protozoa returns occurred only on the second day after therapeutic procedures. Full recovery of the animals occurred within four days, regardless of transfaunation. In conclusion, the ruminal fluid transfer can not be considered crucial for the treatment and convalescence of goats and sheep affected by ARLA.
\end{abstract}

INDEX TERMS: Transfaunation, treatment, ruminal lactic acidosis, goats, sheep, ruminal fluid transfer, fermentative reticulorruminal disease, small ruminants.

\footnotetext{
${ }^{1}$ Recebido em 24 de março de 2017.

Aceito para publicação em 31 de março de 2017.

2 Departamento de Clínicas Veterinárias, Universidade Estadual de Londrina (UEL), Campus Universitário, Cx. Postal 10011, Londrina, PR 86057-970, Brasil. *Autor para correspondência: janlisboa@uel.br
}

\footnotetext{
${ }^{3}$ Departamento de Medicina Veterinária, Faculdade de Ensino Superior e Formação Integral de Garça, Rodovia Comandante João Ribeiro de Barros Km 420, Bairro Rural, Garça, SP 86057-970, Brasil.

4 Departamento de Medicina Veterinária Preventiva, Universidade Estadual de Londrina (UEL), Campus Universitário, Cx. Postal 10011, Londrina, PR 86057-970, Brasil.
} 
RESUMO.- 0 objetivo deste trabalho foi avaliar a importância da transfaunação no tratamento e recuperação de cabras e ovelhas com acidose lática ruminal aguda (ALRA) induzida experimentalmente. Seis cabras $(41,2 \pm 5,6 \mathrm{~kg})$ e seis ovelhas $(46,8 \pm 4,57 \mathrm{~kg})$, não gestantes e não lactantes, receberam $15 \mathrm{~g}$ de sacarose por quilo de peso corporal para indução da enfermidade. A ALRA foi induzida duas vezes em cada animal, com intervalo de 30 dias após recuperação total da primeira indução. Os procedimentos terapêuticos consistiram na remoção do conteúdo ruminal líquido por lavagem e sifonamento com auxílio de sondagem esofágica, e na correção da acidose metabólica com soluções eletrolíticas, contendo lactato ou bicarbonato de sódio, infundidas por via intravenosa. A transfaunação fez parte de apenas um dos tratamentos de cada animal e consistiu na administração por sondagem esofágica de $2 \mathrm{~L}$ de suco ruminal de um bovino sadio. A recuperação completa foi avaliada por exames físicos e exames do suco ruminal realizados até quatro dias após os procedimentos terapêuticos. A eficácia dos protocolos de tratamento, com ou sem transfaunação, foi comparada. 0 protocolo de indução foi efetivo em induzir a enfermidade e as cabras e ovelhas apresentaram sinais clínicos de intensidade máxima (apatia, atonia ruminal, distensão abdominal, diarreia de consistência pastosa a líquida e desidratação moderada) 16 horas após a administração intrarruminal de sacarose, sem distinção entre as espécies. Neste momento, as características do suco ruminal mostraram-se semelhantes aos quadros típicos de ALRA. A frequência de movimentos ruminais se normalizou no terceiro dia após os procedimentos terapêuticos, sem diferença entre as espécies, e independente de terem recebido a transfaunação ou não. A transferência de suco ruminal também não acelerou a recuperação do apetite, que foi considerado normal somente no quarto dia após os procedimentos terapêuticos, em ambas as espécies. Em relação ao líquido ruminal, quando receberam a transfaunação, os caprinos e ovinos apresentaram recuperação das características de cor, odor e consistência mais rapidamente do que quando não receberam. A atividade fermentativa da microbiota ruminal não sofreu influência da transfaunação e se normalizou dois e três dias após os procedimentos terapêuticos nas ovelhas e cabras, respectivamente. A transfaunação promoveu o retorno mais rápido da população de protozoários ruminais, que já foram observados 24 horas após os procedimentos terapêuticos, em ambas as espécies. Quando os animais não receberam a transfaunação, o retorno dos protozoários só ocorreu no segundo dia após os procedimentos terapêuticos. A recuperação completa dos animais estudados ocorreu em até quatro dias, independente da realização da transfaunação ou não. Conclui-se que a transferência de suco ruminal não pode ser considerada medida crucial para o tratamento e convalescença de caprinos e ovinos acometidos por de ALRA.

TERMOS DE INDEXAÇ̃̃O: Transfaunação, tratamento, acidose láctica ruminal aguda, caprinos, ovinos, transferência de suco ruminal, doença fermentativa reticulorruminal, pequenos ruminantes.

\section{INTRODUÇÃO}

A transfaunação, ou seja, a transferência de certo volume de suco ruminal proveniente de um animal sadio para um receptor doente, é um procedimento tradicional e frequentemente utilizado para o tratamento das espécies ruminantes (Lira et al.
2013, DePeters \& George 2014, Smith 2015) e vem sendo praticada há mais de dois séculos (Brag \& Hansen 1994). O líquido ruminal a ser transferido deve ser obtido de um ruminante sadio e adaptado à mesma alimentação que o animal enfermo receberá no período de convalescência (Pugh 2004, Radostits et al. 2007, Smith 2015). A transfaunação é indicada nos casos de indigestões ou sempre que a microbiota ruminal estiver comprometida ou com atividade reduzida, tendo a finalidade de restabelecer a população microbiana e a atividade fermentativa nos pré-estômagos (Pugh 2004, Radostits et al. 2007, Jasmin et al. 2011).

A transfaunação é particularmente recomendada nos casos de acidose láctica ruminal aguda (ALRA), considerada a doença fermentativa pré-estomacal mais grave, uma vez que a maior parte da microbiota é destruída (Smith 2015). Este procedimento tem sido empregado nos casos naturais e de indução experimental dessa enfermidade em bovinos (Maruta \& Ortolani 2002, Leal et al. 2007, Ortolani et al. 2010) e em pequenos ruminantes (Braun et al. 1992, Afonso et al. 2005, Vieira et al. 2006, Miranda Neto et al. 2011).

Apesar da utilização rotineira na clínica buiátrica, a avaliação crítica da sua necessidade ou importância em promover benefícios terapêuticos verdadeiros não foi investigada consistentemente. Estudos científicos a respeito desse procedimento terapêutico são raros (Tankersley et al. 2007, DePeters \& George 2014). A eficácia da transfaunação foi avaliada uma única vez, em vacas após a correção cirúrgica do deslocamento abomasal à esquerda (Rager et al. 2004). Os autores desconhecem estudos dessa natureza nos casos de indigestões primárias, ou mais especificamente, naqueles de origem fermentativa.

O objetivo deste trabalho foi avaliar as mudanças no suco ruminal após a transfaunação em ovelhas e cabras portadoras de ALRA induzida e determinar a importância desse procedimento para o tratamento da enfermidade em questão.

\section{MATERIAL E MÉTODOS}

O projeto de pesquisa foi aprovado pela Comissão de Ética no Uso de Animais da Universidade Estadual de Londrina, sob os protocolos CEUA/UEL 40/2007 e 9165.2012.81.

Animais. Participaram do estudo seis cabras adultas da raça Saanen, com 41,2 $\pm 5,6 \mathrm{~kg}$ de peso corporal, e seis ovelhas adultas mestiças, com $46,8 \pm 4,57 \mathrm{~kg}$ de peso corporal, sadias, não gestantes e não lactantes. Durante todo o período experimental, os animais foram alimentados com feno de capim Coast-cross (Cynodon dactylon) à vontade e com ração comercial para caprinos (Ração Cocari caprinos adultos, Cocari $^{\circledR}$, Mandaguari, Paraná, Brasil) ou para ovinos (Ração ovinos adultos, $\mathrm{SRM}^{\circledR}$, Maringá, Paraná, Brasil), na quantidade de $150 \mathrm{~g} /$ animal duas vezes ao dia, tendo acesso livre a água e a sal mineral (Sal Rural Maringá, SRM ${ }^{\circledR}$, Maringá, Paraná, Brasil). As fêmeas permaneceram alojadas em baias coletivas e passaram por um período de 30 dias de adaptação à dieta antes da primeira indução de ALRA.

Indução da ALRA. Anteriormente à indução, os animais foram transferidos para baias individuais, mantidos em jejum de alimentos sólidos por 18 horas e permaneceram com acesso à água. A ALRA foi induzida com sacarose (Açúcar Cristal Estrela; LDC Bionergia $\mathrm{SA}^{\circledR}$, São Paulo, Brasil) na dose de 15 gramas/kg de peso corporal (Kezar \& Church 1979) diluídos em dois litros de água morna $\left(39^{\circ} \mathrm{C}\right)$ e administrados, por meio de sondagem esofágica, diretamente no interior do rúmen (hora 0 ). 
Cada animal foi submetido à indução da ALRA duas vezes, recebendo a transfaunação em uma das vezes. A segunda indução de ALRA ocorreu, no mínimo, 30 dias após a recuperação completa do primeiro quadro induzido.

Procedimentos terapêuticos. 0 procedimento terapêutico foi iniciado 16 horas após a administração da sacarose (hora 16) e consistiu em lavagem do rúmen com sifonamento para a remoção do conteúdo líquido presente no interior do órgão, seguida de fluidoterapia para correção da acidose metabólica e da desidratação. A lavagem ruminal foi realizada, por meio de sondagem esofágica, com o total de 16 litros de água morna, recuperados por sifonamento com auxílio da compressão manual do abdômen (quatro procedimentos consecutivos, com quatro litros de água de cada vez).

Imediatamente após a lavagem ruminal, foi iniciada a infusão intravenosa de solução eletrolítica ligeiramente hiposmolar $(275 \mathrm{mOsm} / \mathrm{L}$ de osmolaridade calculada), contendo o bicarbonato de sódio ou o lactato de sódio, como composto alcalinizante, em concentração de $84 \mathrm{mEq} / \mathrm{L}$ (Junqueira et al. 2015). A solução foi administrada por infusão contínua, totalizando o volume correspondente a 10\% do peso corporal que cada animal apresentou após a remoção do conteúdo líquido ruminal. A velocidade de infusão foi de $25 \mathrm{~mL} / \mathrm{kg} / \mathrm{h}$, o que correspondeu a quatro horas para a administração de todo o volume (término da infusão na hora 20).

Duas horas após o término da infusão intravenosa (hora 22), outra lavagem ruminal foi executada com o total de 12 litros de água morna (três procedimentos consecutivos, com quatro litros de água de cada vez). Esse procedimento teve a finalidade de garantir que a maior parte do ácido láctico e do açúcar ainda presentes no interior do rúmen fosse removida efetivamente.

Transfaunação. Para garantir a padronização, o suco ruminal a ser transferido foi colhido sempre e exclusivamente de um mesmo bovino adulto, cuja dieta foi mantida sem variação e consistia, regularmente, de feno de capim Coast-cross, oferecido à vontade, e de silagem de sorgo, oferecida em duas refeições no dia (manhã e tarde). A colheita foi realizada por meio da sondagem esofágica com auxílio de um sistema para produção de vácuo em um recipiente de vidro, e sempre ocorreu cinco horas após a oferta matinal de silagem. 0 bovino doador manteve-se clinicamente sadio durante todo o período do experimento. As amostras de suco ruminal transferidas apresentavam características de coloração, odor e consistência normais e pH dentro dos valores fisiológicos (Dirksen et al. 1993), variando de 6,7 a 7,1. Não foram realizadas provas específicas para avaliação da microbiota, mimetizando-se, dessa forma, as condições de rotina de trabalho a campo.

O delineamento experimental adotado foi o cross-over, no qual cada ovelha ou cabra com ALRA induzida foi tratada de duas maneiras: uma com transfaunação e outra sem. A ordem dos tipos de tratamento (com ou sem transfaunação) foi determinada por sorteio. A transfaunação ocorreu após a segunda e última lavagem ruminal (hora 22). Dois litros de suco ruminal fresco, colhidos do bovino doador, foram imediatamente administrados por sondagem esofágica para o interior do rúmen das cabras e das ovelhas estudadas.

Acompanhamento dos animais, exame físico e exames laboratoriais. Após o término da hidratação intravenosa e durante todo o restante do período de observação da recuperação do quadro, as fêmeas receberam, unicamente, feno de capim Coast-cross e água à vontade, permanecendo alojadas em baias individuais.

Exames físicos foram realizados antes da indução (hora 0) e após a mesma a cada oito horas durante quatro dias consecutivos. Foram avaliados temperatura retal, frequências respiratória e cardíaca, frequência dos movimentos ruminais, perímetro abdominal mensurado imediatamente caudal à última costela, estado de hidratação, cor das mucosas, característica das fezes, comportamento e postura. $\mathrm{O}$ apetite foi avaliado subjetivamente (pelo comportamento exibido com a oferta do alimento) e objetivamente, por meio da diferença entre as pesagens do feno oferecido e da sua sobra no cocho.

Amostras de suco ruminal de cada cabra ou ovelha, em volume aproximado de $150 \mathrm{~mL}$, foram coletadas, por sondagem esofágica, nos seguintes momentos: antes da indução (hora 0), no início do procedimento terapêutico (hora 16) e a cada 24 horas por três dias consecutivos (hora 40, hora 64 e hora 88), com a finalidade de avaliar as suas características físico-químicas e a função fermentativa da microbiota ruminal. Foram avaliados cor, odor, consistência, $\mathrm{pH}$ (potenciômetro eletrônico PG1800, Gehaka ${ }^{\circledR}$, São Paulo, SP, Brasil), tempo de redução do azul de metileno (TRAM) e prova de flotação (flutuação e sedimentação) medindo-se o tempo de atividade do sedimento (TAS) (Dirksen et al. 1993). A presença (quantificada por cruzes) e atividade dos protozoários pequenos, médios e grandes foram avaliadas (Dirksen et al. 1993). Realizou-se avaliação morfotintorial da flora bacteriana em esfregaços confeccionados com o suco ruminal e corados com coloração de Gram, estabelecendo-se a proporção entre as bactérias Gram negativas e Gram positivas presentes.

0 tempo necessário para a recuperação completa, considerando-se as funções motora reticulorruminal e fermentativa da microbiota, assim como o apetite, foi computado como critério de comparação entre os dois tipos de tratamento (com ou sem transfaunação).

Análise estatística. A análise de variância de medidas repetidas bifatorial foi empregada para avaliar o efeito do tempo (antes e após a indução), o efeito da transfaunação (com ou sem) e a interação entre os dois fatores sobre as variáveis quantitativas. A análise estatística foi realizada considerando cada espécie em separado. Admitiu-se a probabilidade de erro de 5\%. 0 programa de informática SigmaStat for Windows 3.1 foi empregado para a realização da análise estatística.

\section{RESULTADOS}

A administração intrarruminal de $15 \mathrm{~g} / \mathrm{kg}$ de sacarose provocou o quadro de ALRA nas cabras e nas ovelhas, sem distinção aparente entre as espécies quanto à magnitude dos sinais e à evolução. Dezesseis horas após, todos os animais apresentavam atonia ruminal, taquicardia, distensão abdominal, apatia, desidratação moderada e diarreia, com as fezes variando de pastosas a liquefeitas. A temperatura retal e a frequência respiratória não se alteraram. Após as lavagens ruminais e a hidratação intravenosa, observou-se a remissão dos sinais em todos os animais, exceto a disfunção motora reticulorruminal que se manteve presente. Esse padrão de resposta aos procedimentos terapêuticos foi semelhante nas duas espécies, independente de terem recebido a transfaunação ou não.

A frequência dos movimentos ruminais se reduziu até alcançar a atonia 16 horas após a indução (Fig.1). Essa condição se manteve até o momento em que o feno foi novamente oferecido após o término da infusão intravenosa de fluidos (hora 20). A hipomotilidade ruminal manteve-se presente mesmo após os procedimentos terapêuticos e a frequência fisiológica foi alcançada na hora 56, no caso das ovelhas, e na hora 72, no caso das cabras. Para ambas as espécies, a variação da frequência dos movimentos ruminais não sofreu efeito da realização da transfaunação $(\mathrm{P}>0,05)$. 0 apetite manteve-se diminuído inicialmente e só foi considerado normal ao término do quarto dia após os procedimentos terapêuticos (Fig.2). Aparentemente, a velocidade da recuperação da ingestão 


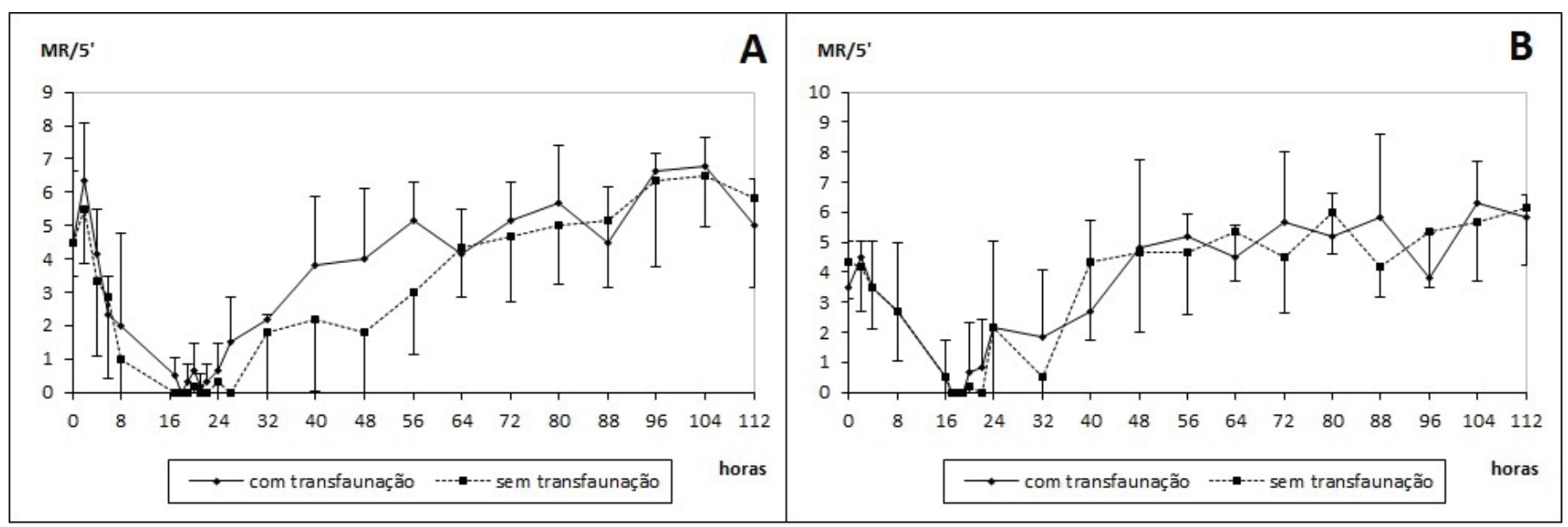

Fig.1. (A) Variação do número de movimentos ruminais em 5 minutos em cabras e (B) ovelhas portadoras de acidose láctica ruminal aguda induzida com sacarose (0 hora), tratadas (16 horas), com ou sem transfaunação (24 horas) e acompanhadas durante quatro dias após o tratamento.

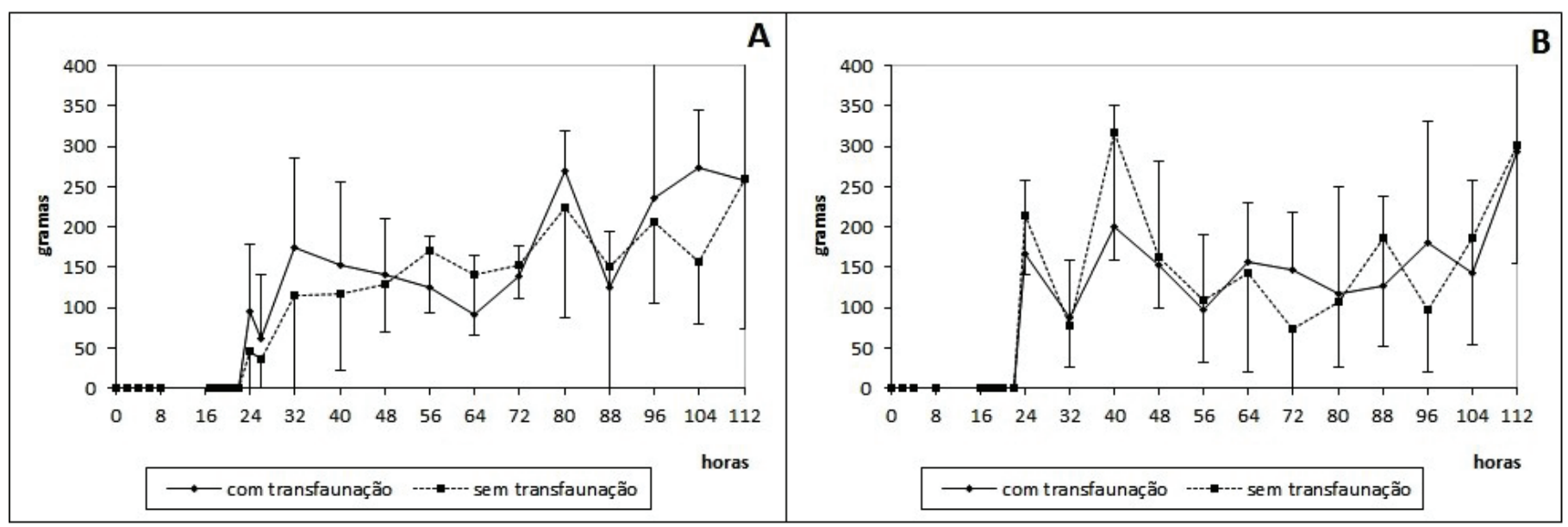

Fig.2. (A) Ingestão voluntária de feno por cabras e (B) ovelhas portadoras de acidose láctica ruminal aguda induzida com sacarose (0 hora), tratadas (16 horas), com ou sem transfaunação (24 horas) e acompanhadas durante 4 dias após o tratamento.

voluntária de feno não foi influenciada pela realização da transfaunação em qualquer uma das espécies.

Os resultados das avaliações seriadas do suco ruminal das cabras e das ovelhas estão apresentados nos Quadros 1 e 2, respectivamente. Com a indução da ALRA, as características físicas do suco ruminal alteraram-se, sem distinção aparente entre as duas espécies. 0 retorno da cor, do odor e da consistência à situação fisiológica ocorreu naturalmente três dias depois (hora 88). Quando os animais receberam a transfaunação o restabelecimento das características originais foi mais rápido, completando-se em dois dias (hora 64).

Dezesseis horas após a indução, o pH do suco ruminal apresentava valores médios acentuadamente reduzidos, tanto nas cabras, quanto nas ovelhas, o que confirma o sucesso da indução da ALRA. A remoção dos ácidos acumulados no interior do rúmen, por meio das lavagens ruminais, foi eficiente para corrigir a acidose ruminal. Valores de $6,43 \pm 0,51$ e de 5,97 $\pm 0,12$ foram observados no suco ruminal das cabras e das ovelhas, respectivamente, logo antes da execução da segunda lavagem ruminal (hora 22). Nos dias seguintes, os valores do pH oscilaram dentro da faixa de variação fisiológica, em ambas as espécies. Tanto nas cabras como nas ovelhas, a transfaunação não interferiu com a variação do $\mathrm{pH}$ do suco ruminal $(\mathrm{P}>0,05)$.

Com a instalação da ALRA, o tempo de redução do azul de metileno (TRAM) elevou-se para além dos 20 minutos, nas duas espécies. 0 retorno aos valores originais ocorreu dois dias após o tratamento (hora 64) nas ovelhas e três dias após o tratamento (hora 88) nas cabras. A variação do TRAM não sofreu influência da transfaunação $(P>0,05)$. 0 tempo de atividade do sedimento (TAS) não apresentou alterações relevantes com a doença, em ambas as espécies, e a transfaunação, igualmente, não interferiu com a sua variação $(\mathrm{P}>0,05)$.

Com a ALRA, os infusórios desapareceram do suco ruminal de todos os animais. Naqueles que receberam a transfaunação, infusórios ativos de diferentes tamanhos já foram visualizados um dia após os procedimentos terapêuticos (hora 40). Nos animais que não receberam a transfaunação, os infusórios começaram a reaparecer somente a partir do segundo dia 
Quadro 1. Características do suco ruminal de cabras portadoras de acidose láctica ruminal aguda induzida com sacarose que receberam transfaunação ou não durante o tratamento. Resultados em diferentes momentos: antes da indução (0 hora), antes do tratamento (16 horas), 1 dia (40 horas), 2 dias (64 horas) e 3 dias (88 horas) após o tratamento

\begin{tabular}{|c|c|c|c|c|c|}
\hline & 0 hora & 16 horas & 40 horas & 64 horas & 88 horas \\
\hline & \multicolumn{5}{|c|}{ Emprego da transfaunação } \\
\hline Cor & Verde oliva & Castanho & Castanho oliva & Verde oliva & Verde oliva \\
\hline Odor & Aromático & Ácido & Indiferente & Aromático & Aromático \\
\hline Consistência & Ligeiramente viscoso & Aquoso & Aquoso & Ligeiramente viscoso & Ligeiramente viscoso \\
\hline $\mathrm{pH}$ & $6,99^{\mathrm{a}} \pm 0,32$ & $4,27^{c} \pm 0,30$ & $6,88^{\mathrm{a}} \pm 0,40$ & $6,88^{\mathrm{ab}} \pm 0,18$ & $6,67^{b} \pm 0,22$ \\
\hline TAS (min) & $3,78^{b} \pm 0,96$ & $7,86^{\mathrm{a}} \pm 2,78$ & $3,9^{b} \pm 2,16$ & $3,86^{\mathrm{b}} \pm 1,38$ & $4,14^{\mathrm{b}} \pm 0,89$ \\
\hline TRAM (min) & $2,85^{\mathrm{d}} \pm 1,36$ & $>20^{\mathrm{a}}$ & $8,3^{b} \pm 3,52$ & $6,13^{\mathrm{c}} \pm 1,76$ & $4,07^{\mathrm{cd}} \pm 1,37$ \\
\hline \multicolumn{6}{|l|}{ Protozoários } \\
\hline grandes & +++ & - & - & + & + \\
\hline médios & +++ & - & + & ++ & ++ \\
\hline pequenos & +++ & - & ++ & ++ & ++ \\
\hline atividade & Ativos & Inativos & Ativos & Ativos & Ativos \\
\hline \multicolumn{6}{|l|}{ Bactérias } \\
\hline Gram + (\%) & $35,83 \pm 6.64$ & $76,66 \pm 8,75$ & $55,83 \pm 12,81$ & $49,16 \pm 4,91$ & $37,5 \pm 7,58$ \\
\hline Gram - (\%) & $64,16 \pm 6.64$ & $23,33 \pm 8,75$ & $44,16 \pm 12,81$ & $50,83 \pm 4,91$ & $62,5 \pm 7,58$ \\
\hline & \multicolumn{5}{|c|}{ Ausência da transfaunação } \\
\hline Cor & Verde oliva & Castanho & Verde claro & Verde claro & Verde oliva \\
\hline Odor & Aromático & Ácido & Indiferente & Indiferente & Aromático \\
\hline Consistência & ligeiramente viscoso & Aquoso & Aquoso & Aquoso & Ligeiramente viscoso \\
\hline $\mathrm{pH}$ & $7,05^{\mathrm{a}} \pm 0,19$ & $4,12^{\mathrm{c}} \pm 0,13$ & $7.26^{\mathrm{a}} \pm 0,59$ & $6,86^{\mathrm{ab}} \pm 0,34$ & $6,46^{\mathrm{b}} \pm 0,20$ \\
\hline TAS (min) & $4,16^{b} \pm 0,37$ & $9,48^{\mathrm{a}} \pm 1,00$ & $6,33^{b} \pm 2,10$ & $4,93^{b} \pm 1,65$ & $4,75^{b} \pm 0,95$ \\
\hline TRAM (min) & $3,31^{\mathrm{d}} \pm 0,77$ & $>20^{\mathrm{a}}$ & $13,06^{b} \pm 5,50$ & $8,13^{c} \pm 2,52$ & $7,04^{\mathrm{cd}} \pm 1,44$ \\
\hline \multicolumn{6}{|l|}{ Protozoários } \\
\hline grandes & +++ & - & - & - & - \\
\hline médios & +++ & - & - & - & + \\
\hline pequenos & +++ & - & - & + & + \\
\hline atividade & Ativos & Inativos & Inativos & Ativos & Ativos \\
\hline \multicolumn{6}{|l|}{ Bactérias } \\
\hline Gram + (\%) & $37,5 \pm 4,18$ & $76,6 \pm 6,05$ & $61,66 \pm 7,52$ & $48,33 \pm 16,02$ & $38,33 \pm 11,69$ \\
\hline Gram - (\%) & $62,5 \pm 4,18$ & $23,33 \pm 6,05$ & $38,33 \pm 7,52$ & $51,67 \pm 16,02$ & $61,66 \pm 11,69$ \\
\hline
\end{tabular}

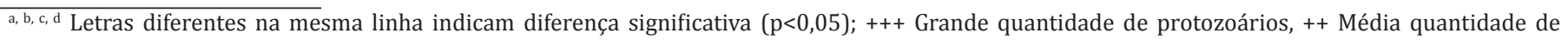
protozoários, + Pouca quantidade de protozoários, - Protozoários ausentes.

após os procedimentos terapêuticos (hora 64). Mesmo assim, somente os de tamanho pequeno foram observados e estavam presentes em número reduzido. Um dia depois (hora 88), essa mesma situação se manteve nas ovelhas, enquanto que nas cabras, pequena quantidade de infusórios de tamanho médio passou a ser também visualizada.

A ALRA modificou a microbiota bacteriana do suco ruminal aumentando a proporção de bactérias Gram positivas, em ambas as espécies. Entretanto, essa mudança foi mais intensa nas ovelhas. Após os procedimentos terapêuticos, observou-se o restabelecimento gradual da microbiota bacteriana, com retorno ao predomínio de bactérias Gram negativas, tanto nas ovelhas quanto nas cabras, sem influência aparente da realização ou não da transfaunação.

\section{DISCUSSÃO}

O protocolo experimental com sacarose foi eficiente para provocar o quadro de ALRA e as fêmeas estudadas manifestaram os sinais típicos da doença, observados em casos naturais (Braun et al. 1992, Vieira et al. 2006, Leal et al. 2007) ou induzidos (Afonso et al. 2002a, 2002b, 2005, Maruta \& Ortolani 2002, Miranda Neto et al. 2005, Ortolani et al. 2010). Apesar de a hipertermia ter sido relatada em caprinos e ovinos acometidos (Braun et al. 1992, Afonso et al. 2002b, Miranda Neto et al. 2011), essa alteração não estava presente nos animais deste estudo.

A inibição da atividade motora reticulorruminal observada nos animais do presente trabalho pode ser explicada pela redução do $\mathrm{pH}$ do suco ruminal em função do ácido láctico acumulado no interior do rúmen (Huber 1976, Dirksen et al. 1993, Smith 2015). A estase ruminal nesses casos pode ser considerada um mecanismo de defesa, pois diminui a absorção do ácido láctico no intestino e evita o agravamento da acidose metabólica (Huber 1976). A remoção do ácido láctico acumulado, por meio das lavagens ruminais, contribuiu para o restabelecimento gradativo da atividade motora pré-estomacal nas cabras e ovelhas estudadas.

Os procedimentos terapêuticos adotados foram eficazes para acelerar o retorno à saúde em todos os animais estudados. Tomando-se como base os restabelecimentos da frequência dos movimentos ruminais e das características do suco ruminal, 
Quadro 2. Características do suco ruminal de ovelhas portadoras de acidose láctica ruminal aguda induzida com sacarose que receberam transfaunação ou não durante o tratamento. Resultados em diferentes momentos: antes da indução (0 hora), antes do tratamento (16 horas), 1 dia (40 horas), 2 dias (64 horas) e 3 dias (88 horas) após o tratamento

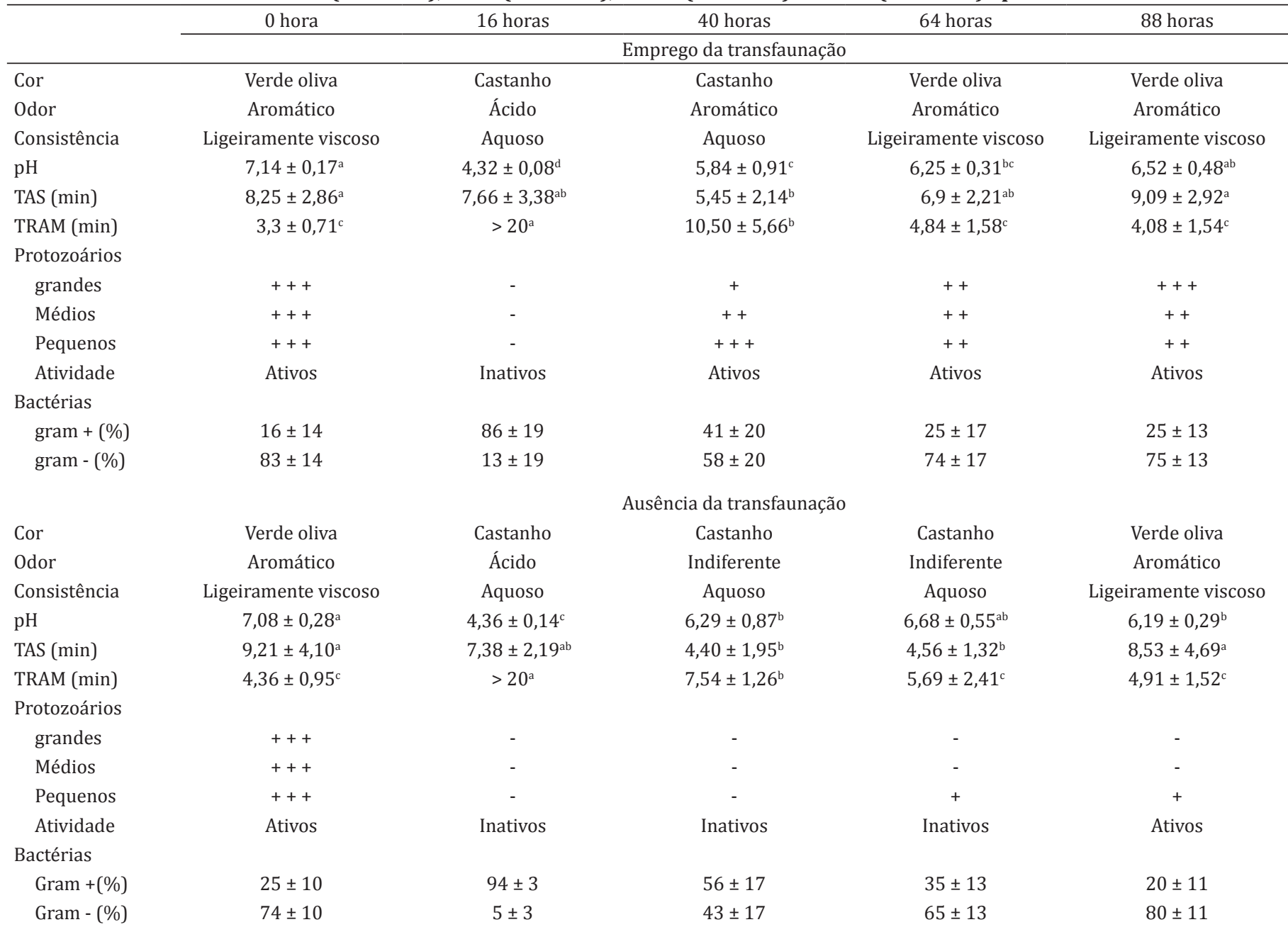

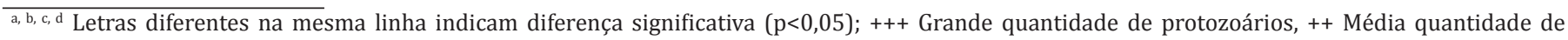
protozoários, + Pouca quantidade de protozoários, - Protozoários ausentes.

pode-se afirmar que as cabras e as ovelhas recuperaram a saúde no terceiro dia após o tratamento. A avidez completa pelo alimento, no entanto, retornou mais tarde, ao final do quarto dia. Em outros estudos de indução de ALRA com sacarose em cabras e em ovelhas, nos quais os animais não foram tratados porque o intuito era acompanhar a evolução natural da doença, a recuperação foi mais tardia e o início da melhora clínica foi relatado a partir das 48 horas após a indução (Afonso et al. 2002a, 2002b, Miranda Neto et al. 2005, 2011).

Em relação ao suco ruminal, as alterações observadas antes dos procedimentos terapêuticos foram características dos quadros de ALRA (Dirksen et al. 1993, Smith 2015) e compatíveis com as observações de outros estudos de indução experimental com sacarose (Kezar \& Church 1979, Cao et al. 1987, Afonso et al. 2002b, Miranda Neto et al. 2005, 2011). A cor tornou-se castanha, ao invés da coloração amarelada a cinza leitosa esperada nos casos de ocorrência natural da doença (Braun et al. 1992, Dirksen et al. 1993, Smith 2015). Essa coloração pode ser explicada pelo fato de a sacarose, e não o milho, ter sido o agente causador da enfermidade.
O odor ácido e a consistência aquosa são padrão da ALRA, como consequência do acúmulo de ácido láctico e do fluxo de líquidos para o interior do rúmen (Dougherty et al. 1975, Radostits et al. 2007).

$\mathrm{O}$ retorno do $\mathrm{pH}$ aos valores fisiológicos, em ambas as espécies, observado logo antes da realização da segunda lavagem ruminal, é a prova de que as medidas terapêuticas adotadas foram eficientes para a correção do quadro de ALRA. Nos estudos em que a doença foi induzida com sacarose em caprinos e em ovinos, o reestabelecimento dos valores de $\mathrm{pH}$ do suco ruminal ocorreu das 48 até 144 horas após a indução (Kezar \& Church 1979, Afonso et al. 2002b, Miranda Neto et al. 2005). 0 intervalo de tempo menor observado no presente trabalho pode ser explicado pela adoção da lavagem ruminal com remoção do conteúdo líquido ruminal alterado.

O TRAM maior do que 20 minutos observado antes dos procedimentos terapêuticos é coerente com outros relatos (Basak et al. 1993, Afonso et al. 2002b, Maruta \& Ortolani 2002), e ocorre devido à inativação da flora microbiana pré-estomacal. A restauração do ambiente ruminal, com a retirada do ácido acumulado por meio das lavagens ruminais, 
foi fundamental para o retorno aos valores fisiológicos em menor tempo do que o relatado em outros estudos, nos quais a lavagem ruminal não foi realizada (Miranda Neto et al. 2005, 2011). Dentre os métodos de avaliação empregados, o TRAM é o único indicador objetivo da atividade fermentativa da microbiota ruminal (Dirksen et al. 1993, Smith 2015) e o seu retorno a valores fisiológicos reflete a recuperação da capacidade metabólica das bactérias.

Existem informações conflitantes sobre o comportamento do TAS em quadros de ALRA. Pode estar reduzido, em decorrência da mudança da microbiota bacteriana de Gram negativa para Gram positiva (Randhawa et al. 1989), aumentado (Basak et al. 1993), ou inalterado (Miranda Neto et al. 2005, 2011), como o observado neste estudo.

A ausência de infusórios no suco ruminal 16 horas após a indução também já foi relatada (Braun et al. 1992, Afonso et al. 2002b, 2005, Miranda Neto et al. 2005, 2011) e se deve ao aumento da acidez no interior do órgão. Os protozoários perdem sua atividade quando o pH ruminal está abaixo de 5,5 e sofrem lise quando o $\mathrm{pH}$ alcança valores inferiores a 5,0 (Hungate 1966). O aumento gradual no número de pequenos infusórios vivos começa a ser observado entre 48 e 96 horas após a indução experimental de ALRA (Miranda Neto et al. 2005, 2011), assim como descrito no presente trabalho quando os animais não receberam a transfaunação. 0 retorno dos infusórios no suco ruminal é mais rápido quando a transfaunação é realizada e isso foi demonstrado, pela primeira vez, no presente trabalho.

0 predomínio das bactérias Gram positivas, 16 horas após a indução, é coerente com relatos anteriores (Hungate 1966, Owens et al. 1998, Miranda Neto et al. 2005, 2011) e reflete o crescimento de bactérias resistentes ao meio ácido, sendo elas próprias as produtoras do ácido láctico. 0 restabelecimento da microbiota normal, com maior proporção de bactérias Gram negativas, ocorre, gradativamente, após a correção do ambiente ruminal (Afonso et al. 2002b, Miranda Neto et al. 2005). Diferente do que ocorreu com os protozoários, a transfaunação não influenciou a velocidade do retorno das bactérias à sua proporção fisiológica.

Diante dos resultados obtidos no presente estudo, pode-se afirmar que a realização da transfaunação não contribuiu para abreviar o período de convalescência dos animais. Não acelerou a recuperação da função motora reticulorruminal ou o retorno ao apetite, e não interferiu com as variações de pH, TRAM e TAS, ou seja, não afetou o restabelecimento da função fermentativa. Contudo, é inegável que a transfaunação desempenha papel importante no restabelecimento mais rápido das características físicas do suco ruminal e da população de infusórios no rúmen após quadros de ALRA.

É difícil definir a relevância biológica e clínica desse achado porque, ao contrário das bactérias ruminais, pouco se compreende ainda sobre o papel que os infusórios desempenham no metabolismo fermentativo pré-estomacal. Dentre as suas principais funções estão o controle da microbiota ruminal como um todo, pois são predadores de bactérias, leveduras e fungos; a manutenção da anaerobiose por consumirem oxigênio; o efeito indireto como fonte de nutrientes por depositarem polissacarídeos, lipídios e proteínas em seu interior; e a estabilização do pH ruminal por consumirem uma porcentagem do amido da dieta e diminuírem o potencial redox, criando um ambiente adequado para o crescimento bacteriano, principalmente da microbiota celulolítica (Lucci 1997, Cunningham 2004, DePeters \& George 2014). Entretanto, diferentemente das bactérias, os infusórios não são essenciais para a manutenção da atividade fermentativa pré-estomacal e da homeostase e sobrevivência dos ruminantes (Carvalho et al. 2005). Segundo Bird \& Leng (1978) a eliminação dos protozoários ruminais, por exemplo, aumenta o ganho de peso diário em animais que ingerem dieta rica em energia. Além disso, apesar de contribuírem para a síntese proteica dentro do rúmen, a maioria dos infusórios morre e é degradada ainda no interior do órgão, sendo reduzido o fluxo dessas proteínas para o restante do trato digestório (Leng 1982).

Ainda que existam indicações para o uso da transfaunação em diferentes enfermidades ruminais (Brag \& Hansen 1994, Radostits et al. 2007, DePeters \& George 2014, Smith 2015) e apesar do seu emprego frequente na clínica buiátrica, os autores desconhecem qualquer investigação científica que tenha avaliado criticamente os efeitos desse procedimento no tratamento das enfermidades fermentativas reticulorruminais. 0 único estudo desenvolvido com esse objetivo avaliou vacas em início da lactação acometidas por deslocamento abomasal que receberam ou não a transfaunação no pós-operatório (Rager et al. 2004).

As seguintes vantagens podem ser atribuídas à transfaunação e não devem ser desconsideradas. 0 suco ruminal de animais sadios contém ácidos graxos voláteis, bicarbonato, proteínas e microorganismos intactos, além de possíveis outros componentes não identificados, que são diretamente transferidos para o interior do rúmen do animal enfermo (DePeters \& George 2014). Há evidências que os nutrientes presentes no suco ruminal transferido podem beneficiar o crescimento de bactérias, protozoários e fungos restabelecendo a população microbiana normal do órgão do animal enfermo (Russell \& Hespell 1981, Miura et al. 1983, Krause et al. 2013). Além disso, o preenchimento do rúmen e retículo pode estimular os receptores de tensão de baixo limiar da parede ruminal e provocar melhora na motilidade reticulorruminal (Forbes \& Barrio 1992, Smith 2015).

0 volume de suco ruminal a ser transferido e a frequência de administrações são variáveis nos diferentes relatos e não há um protocolo estabelecido. A transferência de um a dois litros de suco ruminal é, geralmente, indicada para o tratamento de caprinos ou ovinos, com administrações únicas (Braun et al. 1992, Vieira et al. 2006, Lira et al. 2013, DePeters \& George 2014) ou, eventualmente, repetidas (Braun et al. 1992); e o doador pode ser da espécie bovina devido à facilidade de obtenção de volumes maiores de suco ruminal (Braun et al. 1992, Pugh 2004, DePeters \& George 2014). É importante reforçar que a sobrevivência da microbiota presente no suco ruminal transferido depende, principalmente, das condições existentes no ambiente ruminal do indivíduo enfermo receptor (Kezar \& Church 1979, DePeters \& George 2014). No presente estudo, as lavagens ruminais, que antecederam a transfaunação, promoveram a remoção do ácido láctico acumulado e a correção do $\mathrm{pH}$ do suco ruminal, garantindo ambiente favorável para o novo crescimento microbiano e condições adequadas para o melhor resultado da transfaunação. Nenhum desses aspectos técnicos pode ser apontado, portanto, como responsável pela ausência de vantagem terapêutica observada para a transfaunação nas cabras e nas ovelhas estudadas. 
Os resultados obtidos não devem servir para desencorajar a prática da transfaunação, principalmente, se houver facilidade para a sua execução, com animais fistulados próximos ao animal doente ou com a presença de material que facilite a coleta de grande quantidade de suco ruminal por sondagem esofágica. Nessas condições, a transfaunação deve ser realizada. Todavia, se a obtenção do suco ruminal para ser transferido for difícil, essa prática não é imprescindível para a recuperação do animal acometido pela ALRA.

Deve-se salientar, por fim, que, nas condições do presente estudo, o tratamento da ALRA induzida foi realizado em momento inicial da evolução da doença. É incerto afirmar que a transfaunação seja um procedimento terapêutico complementar dispensável quando o tratamento for instituído após período mais prolongado da evolução da doença. Novos estudos devem ser realizados para elucidar a importância da transfaunação em enfermidades fermentativas com evolução crônica.

\section{CONCLUSÕES}

Com base nos critérios clínicos pode-se concluir que todos os animais estudados retornaram à condição de saúde quatro dias após o tratamento, independente de terem recebido a transfaunação.

A transferência de suco ruminal de um animal sadio acelerou a recuperação da população de protozoários no rúmen dos animais doentes e o retorno das características físicas do suco ruminal.

Nas condições deste estudo, a transfaunação não se comprovou como uma medida de importância crítica para o sucesso do tratamento de caprinos e ovinos acometidos pela acidose lática ruminal aguda (ALRA).

Agradecimentos.- Júlio A.N. Lisbôa é bolsista de produtividade do Conselho Nacional de Desenvolvimento Científico e tecnológico (CNPq).

\section{REFERÊNCIAS}

Afonso J.A.B., Ciarlini P.C., Kuchembuck M.R.G., Kohayagawa A., Feltrin L.P.Z., Ciarlini L.D.R.P., Laposy C.B., Mendonça C.L. \& Takahira R.K. 2002a. Metabolismo oxidativo dos neutrófilos de ovinos tratados com a monensina sódica e experimentalmente submetidos à acidose ruminal. Pesq. Vet. Bras. 22(4):129-134. http://dx.doi.org/10.1590/S0100-736X2002000400001.

Afonso J.A.B., Kuchembuck R.G., Feltrin L.P.Z., Laposy C.B., Kohayagawa A., Mendonça C.L. \& Takahira R.K. 2002b. Efeito da Monensina sódica sobre as características do suco rumenal na acidose láctica experimental em ovinos. Revta Bras. Med. Vet. 24(5):203-210.

Afonso J.A.B., Kuchembuck M.R.G., Feltrin L.P.Z., Laposy C.B., Kohayagawa A., Mendonça C.L. \& Takahira R.K. 2005. Avaliação do uso da monensina sódica na prevenção da acido láctica ruminal experimental em ovinos. Vet. Notícias 11(1):35-43.

Basak D.N., Span S. \& Chakrabarti A. 1993. Physicochemical and microbial changes in rumen liquor of experimentally induced lactic acidosis in goats. Indian J. Anim. Sci. 63(3):263-267.

Bird S.H. \& Leng R.A. 1978. The effects of defaunation of the rumen on the growth of cattle on low-protein high-energy diets. Brit. J. Nutr. 40(1):163167. http://dx.doi.org/10.1079/BJN19780108. PMid:667001.

Brag S. \& Hansen H.J. 1994. Treatment of ruminal indigestion according to popular belief in Sweden. Rev. Scient. Tech. Off. Int. Epizoot., Paris, 13(2):529-535. http://dx.doi.org/10.20506/rst.13.2.782. PMid:8038450.
Braun U., Rihs T. \& Schefer U. 1992. Ruminal lactic acidosis in sheep and goats. Vet. Rec. 130(16):343-349. http://dx.doi.org/10.1136/vr.130.16.343. PMid:1595174.

Cao G.R., English P.B., Filippich L.J. \& Inglis S. 1987. Experimentally induced lactic acidosis in the goat. Aust. Vet. J. 64(12):367-370. http://dx.doi. org/10.1111/j.1751-0813.1987.tb09605.x. PMid:3452303.

Carvalho F.A.N., Barbosa F.A. \& McDowell L.R. 2005. Fisiologia digestiva, p.21-58. In: Ibid. (Eds), Nutrição de Bovinos a Pasto. $2^{\mathrm{a}}$ ed. Gradual Editora Gráfica, Belo Horizonte. 428p.

Cunningham J.G. 2004. Digestão: os processos fermentativos, p.288-311. In: Ibid. (Ed.), Tratado de Fisiologia Veterinária. $3^{\mathfrak{a}}$ ed. Guanabara Koogan, Rio de Janeiro.

DePeters E.J. \& George L.W. 2014. Rumen transfaunation. Immunol. Lett. 162(2):69-76. http://dx.doi.org/10.1016/j.imlet.2014.05.009. PMid:25262872.

Dirksen G., Gründer H.D. \& Stöber M. 1993. Sistema digestivo, p.166-228. In Ibid. (Eds.), Rosenberger: Exame Clínico dos Bovinos. 3ae ed. Guanabara Koogan, Rio de Janeiro. 420p.

Dougherty R.W., Riley J.L. \& Cook H.M. 1975. Changes in motility and pH in the digestive tract of experimentally overfed sheep. Am. J. Vet. Res. 36(6):827-829. PMid:238438.

Forbes J.M. \& Barrio J.P. 1992. Abdominal chemo and mechanosensitivy in ruminants and its role in the control of food intake. Exp. Physiol. 77(1):2750. http://dx.doi.org/10.1113/expphysiol.1992.sp003581. PMid:1543591.

Huber T.L. 1976. Physiological effects of acidosis on feedlot cattle. J. Anim. Sci. 43(4):902-909. http://dx.doi.org/10.2527/jas1976.434902x. PMid:789318.

Hungate R.E. 1966. Possible modifications in ruminant feeding practices, p.419-441. In: Ibid. (Eds.), The Rumen and its Microbes. Academic Press, New York. 533p.

Jasmin B.H., Boston R.C., Modesto R.B. \& Schaer T.P. 2011. Perioperative ruminal $\mathrm{pH}$ changes in domestic sheep (Ovis aries) housed in a biomedical research setting. J. Am. Assoc. Lab. Anim. Sci. 50(1):27-32. PMid:21333159.

Junqueira J.R.C., Balarin M.R.S., Flaiban K.K.M.C., Barbosa D.S. \& Lisbôa J.A.N. 2015. Efeito alcalinizante de soluções eletrolíticas intravenosas com concentrações elevadas de lactato de sódio infundidas em bezerros sadios. Arq Bras. Med. Vet. Zootec. 67(1):15-24.http://dx.doi.org/10.1590/1678-6754.

Kezar W.W. \& Church D.C. 1979. Ruminal changes during the onset and recovery of induced lactic acidosis in sheep. J. Anim. Sci. 49(5):1161-1167. http://dx.doi.org/10.2527/jas1979.4951161x. PMid:44285.

Krause D.O., Nagaraja T.G., Wright A.D.G. \& Callaway T.R. 2013. Board-invited review: rumen microbiology: leading the way in microbial ecology. J. Anim. Sci. 91(1):331-341. http://dx.doi.org/10.2527/jas.2012-5567. PMid:23404990.

Leal M.L.R., Maruta C.A. \& Ortolani E.L. 2007. Uso de bicarbonato e L-lactato para correção da acidose metabólica sistêmica em bovinos com acidose láctica ruminal aguda. Arq. Bras. Med. Vet. Zootec. 59(4):971-976. http:// dx.doi.org/10.1590/S0102-09352007000400024.

Leng R.A. 1982. Dynamics of protozoa in the rumen of sheep. Brit. J. Nutr. 48(2):399-415. http://dx.doi.org/10.1079/BJN19820123. PMid:6810918.

Lira M.A.A., Simões S.V.D., Riet-Correa F., Pessoa C.M.R., Dantas A.F.M. \& Miranda Neto E.G. 2013. Doenças do sistema digestório de caprinos e ovinos no semiárido do Brasil. Pesq. Vet. Bras. 33(2):193-198. http:// dx.doi.org/10.1590/S0100-736X2013000200010.

Lucci C.D.S. 1997. Energia e alimentação, p.43-61. In: Ibid. (Eds.), Nutrição e Manejo de Bovinos Leiteiros. Manole, São Paulo. 169p.

Maruta C.A. \& Ortolani E.L. 2002. Susceptibilidade de bovino das raças Jersey e Gir à acidose láctica ruminal: I, variáveis ruminais e fecais. Ciência Rural 32(1):55-59. http://dx.doi.org/10.1590/S0103-84782002000100010.

Miranda Neto E.G., Afonso J.A.B., Mendonça C.L. \& Almeida M.Z.P.R.B. 2005. Estudo clínico e características do suco ruminal de caprinos com acidose 
láctica induzida experimentalmente. Pesq. Vet. Bras. 25(2):73-78. http:// dx.doi.org/10.1590/S0100-736X2005000200002.

Miranda Neto E.G., Silva S.T.G., Mendonça C.L., Drummond A.R.F. \& Afonso J.A.B. 2011. Aspectos clínicos e a bioquímica ruminal de caprinos submetidos à acidose láctica experimental e suplementados ou não com monensina sódica. Pesq. Vet. Bras. 31(5):416-424. http://dx.doi.org/10.1590/S0100736X2011000500009.

Miura H., Horiguchi M., Ogimoto K. \& Matsumoto T. 1983. Nutrition interdependence among rumen bacteria during celulose digestion in vitro. Appl. Environ. Microbiol. 45(2):726-729. PMid:16346223.

Ortolani E.L., Maruta C.A. \& Minervino A.H.H. 2010. Aspectos clínicos da indução experimental de acidose láctica ruminal em zebuínos e taurinos. Braz. J. Vet. Res. Anim. Sci. 47(4):253-261. http://dx.doi.org/10.11606/ issn.1678-4456.bjvras.2010.26823.

Owens F.N., Secrist D.S., Hill W.J. \& Gill D.R. 1998. Acidosis in cattle: review. J. Anim. Sci. 76(1):275-286. http://dx.doi.org/10.2527/1998.761275x. PMid:9464909.

Pugh D.G. 2004. Enfermidades do sistema gastrointestinal, p.77-118. In: Ibid. (Ed.), Clínica de Ovinos e Caprinos. Editora Roca, São Paulo.

Radostits O.M., Gay C.C., Hinchcliff K.W. \& Constable P.D. 2007. Diseases of the alimentary tract II, p.293-382. In: Ibid. (Eds), Veterinary Medicine: a textbook of the diseases of cattle, horses, sheep, pigs and goats. 10th ed. Saunders Elsevier, Philadelphia.
Rager K.D., George L.W., House J.K. \& DePeters E.J. 2004. Evaluation of rumen transfaunation after surgical correction of left-sided displacement of the abomasum in cows. J. Am. Vet. Med. Assoc. 225(6):915-920. http://dx.doi. org/10.2460/javma.2004.225.915. PMid:15485053.

Randhawa S.S., Ahuja A.K. \& Rathor S.S. 1989. Effect of lactic acidosis on microbial and biochemical changes in rumen liquor of buffalo calves. Indian J. Vet. Med. 9(1):1-7.

Russell J.B. \& Hespell R.B. 1981. Microbial Rumen Fermentation. J. Dairy Sci. 64(6):1153-1169. http://dx.doi.org/10.3168/jds.S0022-0302(81)82694-X. PMid:7024344.

Smith B.P. 2015. Indigestion in ruminants, p.777-799. In: Ibid. (Ed.), Large Animal Internal Medicine. 5th ed. Elsevier Mosby, St Louis.

Tankersley N.S., DePeters E.J. \& Graham T.W. 2007. Case study: effects of water, fresh cow YMCP Plus, and rumen fluid transfaunate supplementation following calving on milk yield, reproductive efficiency, and incidence of common health disorders in Holstein cows. Prof. Anim. Scient. 23(5):513520. http://dx.doi.org/10.1532/S1080-7446(15)31013-5.

Vieira A.C.S., Mendonça J.A.B., Mendonça C.L., Costa N.A. \& Souza M.I. 2006. Estudo retrospectivo da acidose láctica em caprinos e ovinos atendidos na Clínica de bovinos, Campus Garunhuns/UFPRE. Agraria 1(1):97-101. http://dx.doi.org/10.5039/agraria.v1i1a598. 